Research Article

\section{Immunohistochemical expression of Nestin as Cancer Stem Cell Marker in gliomas}

\author{
Rasha Mokhtar Abdelkareem ${ }^{1 *}$, Afaf T Elnashar ${ }^{1}$, Khaled Nasser \\ Fadle $^{2}$ and Eman MS Muhammad ${ }^{1}$
}

'Departments of Pathology, Sohag University, Egypt

${ }^{2}$ Departments of Neurosurgery, Sohag University, Egypt

\section{Abstract}

Background: Gliomas represent the most frequent primary tumors of central nervous system (CNS), contributing to more than half of the incidence of brain tumors. Cancer stem cell markers (CSC) identify a group of patients at high risk for progression. Nestin is an intermediate filament (IF) protein was first described as a neural stem cell/progenitor cell marker. Nestin-positive neuroepithelial stem cells are detected in the subventricular zone of the human adult brain and they remain mitotically active throughout adulthood. The expression of Nestin in gliomas has been suggested to be related to dedifferentiation, improved cell motility, invasive potential and increased malignancy. This study aims to investigate Nestin immunohistochemical expression in different types of glioma and its correlation with different clinicopathological parameters.

Materials and Methods: Nestin immunostaining was studied in 60 specimens of glioma using avidin-biotin peroxidase method.

Results: Nestin was strongly expressed in $11 / 60$ (18.33\%), moderately expressed in 29/60 (48.33\%) and weekly expressed in $15 / 60(25 \%)$ of studied gliomas. A significant positive correlation was found between Nestin expression and histologic type $(p<0.001)$ and increasing grade of gliomas $(p<0.001)$

Conclusion: Increased Nestin expression is correlated with tumor progression, increasing grade and poor prognostic parameter of glioma. Nestin is a useful marker for detection of CSC in high-grade glioma which is responsible for resistance to chemo-radiotherapy and may serve as a predictor for patient outcomes.

\section{More Information}

*Address for Correspondence: Rasha Mokhtar Abdelkareem, Departments of Pathology, Sohag University, Egypt, Tel: 01064641550 ; Email: elnasharafaf@yahoo.com

Submitted: 31 October 2019

Approved: 08 November 2019

Published: 11 November 2019

How to cite this article: Abdelkareem RM, Elnashar AT, Fadle KN, Muhammad EMS. Immunohistochemical expression of Nestin as Cancer Stem Cell Marker in gliomas. J Neurosci Neurol Disord. 2019; 3: 162-166.

DOI: dx.doi.org/10.29328/journal.jnnd.1001027

ORCiD: orcid.org/0000-0003-1079-2112

Copyright: @ 2019 Abdelkareem RM, et al. This is an open access article distributed under the Creative Commons Attribution License, which permits unrestricted use, distribution, and reproduction in any medium, provided the original work is properly cited.

Keywords: Nestin; Cancer stem cell; Gliomas Abbreviations: CNS: Central Nervous System; CSC: Cancer Stem Cell markers; IHC: Immunohistochemistry; IRS: Immunoreactive Score

Check for updates

\section{Introduction}

Gliomas are the most common brain tumors, contributing to more than half of the incidence of brain tumors [1]. They comprise a heterogeneous group of neuroectodermal tumors that arise from the glia cells that may give rise to astrocytomas, oligodendrogliomas and ependymomas, respectively.

In recent years, advances in the understanding of lowgrade glioma (LGG) biology have driven new paradigms in molecular markers, diagnostic imaging, operative techniques and technologies, and adjuvant therapies. Taken together, these developments are collectively pushing the envelope toward improved quality of life and survival [2]. Gliomas are responsible for approximately 13,000 cancer-related deaths in the United States each year [3]. In Egypt, CNS neoplasms represent $1 \%-2 \%$ of all human neoplasms with high grade gliomas being the most common types [4]. Glioma develops through dedifferentiation of cells constituting the mature brain. However, a series of studies has reported the close involvement of Cancer stem cells (CSCs) in the mechanism of the development of glioma [5].

The search for prognostic and predictive biomarkers in gliomas is an area of considerable interest because patients respond differently to treatment and have different prognosis [6]. Some researchers suggest that tumor biology and resistance to treatment are closely connected to the existence of CSCs [7]. The importance of CSCs for estimating the prognosis of patients with glioma has therefore been widely investigated using several markers closely related to the presence of these cells [8]. The CSCs are responsible for resistance of glioblastomas multiform (GBM) to radiotherapy and chemotherapy, thereby contributing to poor survival of 
these patients [9]. The importance of CSCs in estimating the prognosis of patients with gliomas has therefore been widely investigated using several markers closely related to the presence of these cells [10]. Nestin is a class VI intermediate filament (IF) protein that was first described as a neural stem/ progenitor cell marker [11]. Neuroepithelial stem cells can differentiate into neurons, oligodendrocytes, and astrocytes, and Nestin has been shown to be down-regulated completely disappeared during such differentiation [12]. An investigation of Nestin as a cell surface marker of CSCs showed that the efficiency of diagnosis and treatment of brain malignancies can be ameliorated by determining these cell surface markers [13]

\section{Patients and Methods}

\section{Tissue samples}

Formalin-fixed, paraffin-embedded brain tumor tissue blocks from sixty patients were selected prospectively from specimens that were delivered to Pathology Laboratory from Neurosurgery Department, Faculty of Medicine, Sohag University during the period from January 2016 to July 2018. The research was approved from the ethical committee. Gliomas were graded in accordance with the WHO, 2016 grading system, based on specific histopathological characteristics such as cellularity, nuclear atypia, mitotic activity, microvascular proliferation and necrosis.

\section{Immunohistochemistry}

After evaluating Hematoxylin and Eosin stained slides, serial sections from each block were used for Immunohistochemistry (IHC) of Nestin using avidin biotin peroxidase complex method. A dilution of 1:150 from Mouse monoclonal antibody against human Nestin (Clone 10C2, Cat. \# GTX30671, Gene Tex) was used.

\section{Scoring of immunoreactions and statistical analyses}

Nestin expression appeared as brownish cytoplasmic staining. The immunoreactive score (IRS) was determined by multiplyingan estimate ofthepercentageoftheimmunoreactive cells (Proportion score; PS) with an estimate of the staining intensity (intensity score; IS) according to Arai, et al. [14]. A proportion score was defined as the percentage of positively stained cells: $0=$ negative,$<30 \%$ positive tumor cells $(+), 30 \%$ $60 \%$ positive tumor cells $(++),>60 \%$ positive tumor cells $(+++)$. An intensity score was defined as the staining intensity of positive tumor cells: No staining $=0$, Weak staining $=1$, Medium staining $=2$, Strong staining $=3$. An IRS of 1-3 was considered weak, 4 and 6 was moderate and 9 was considered strong.

\section{Statistical analysis}

Data was analyzed using SPSS program version 17.0. Quantitative data was expressed as means \pm standard deviation, median and range. Qualitative data was expressed as number and percentage. The data were tested for normality using Shapiro-Wilk test. The nonparametric Mann-Whitney test, Kruskal-Wallis test and Spearman's correlation were used for data which wasn't normally distributed. $p>0.05$ was considered statistically significant and $>0.001$ was considered highly significant.

\section{Results}

The age range of the studied patients was wide $1.5-72$ years, with mean \pm SD was $38.23 \pm 22.41$ years, the median age was 44 years. The male to female ratio was $1.14: 1$. The representative $\mathrm{H} \& \mathrm{E}$ stained sections of the collected 60 specimens of gliomas were evaluated according to the WHO classification [15], into the following histological types:

Seven 7/60 (11.7\%) cases were pilocytic astrocytoma, twenty-one 21/60 (35\%) cases diffuse astrocytoma, five $5 / 60(8.3 \%)$ cases ependymoma, five 5/60 (8.33\%) cases oligodendroglioma, nine $9 / 60 \quad(15 \%)$ cases anaplastic astrocytoma, two 2/60 (3.33\%) cases anaplastic ependymoma, and eleven 11/60 (18.33\%) cases glioblastoma multiform. Glioma was graded according to the WHO grading system [15] into four grades according histological finding

Seven cases $(7 / 60 ; 11.7 \%)$ grade I; with low cellularity and no mitosis or necrosis. Thirty-one cases (31/60; 51.67\%) grade II; with moderate cellularity, pleomorphism and nuclear atypia. Eleven cases $(11 / 60 ; 18.33 \%)$ grade III; featuring high cellularity, nuclear atypia and brisk mitotic activity. Eleven cases $(11 / 60 ; 18.33 \%)$ grade IV; featuring high cellularity, pleomorphism, brisk mitosis, microvascular proliferation and geographic necrosis. Nestin expression appeared as brownish cytoplasmic staining. Nestin expression varied among different types and grades of gliomas (Table 1). Nestin was expressed in 55/60 (91.7\%) of studied glioma; being weakly expressed in 15/60 (25\%), moderately expressed in $29 / 60$ (48.33\%) and strongly expressed in 11/60 (18.33\%) of the studied cases. There was significant correlation between Nestin expression and both histological type $(p<0.001)$, and tumor grade $(p<0.001)$ (Graphs 1,2). However, there is no statistical correlation between Nestin expression and age, sex of the patients, tumor size or tumor site (Figure 1).

\section{Disscussion}

Our study included 60 specimens of gliomas investigated for Nestin expression. The IRS of Nestin was studied in relation to clinicopathological variables (age, sex, tumor site, size, histological types and tumor grade). This study revealed that Nestin was expressed in about 55/60 (91.7\%) of gliomas. This expression was strong in 11/60 (18.33\%); 8/60 (13.33\%) glioblastoma multiform, and 3/60 (5\%) anaplastic astrocytoma. Nestin was moderately expressed in 29/60 (48.33\%) of studied gliomas; $15 / 60 \quad(25 \%)$ diffuse astrocytoma, 2/60 (3.33\%) ependymoma, 6/60 (10\%) anaplastic astrocytoma, 2/60 (3.33\%) anaplastic ependymoma, 3/60 (5\%) glioblastoma multiform and 1/60 


\begin{tabular}{|c|c|c|c|c|c|c|}
\hline \multirow[b]{2}{*}{ Clinico-pathological Parameter } & \multirow[b]{2}{*}{ NO of cases } & \multicolumn{4}{|c|}{ Nestin expression } & \multirow[b]{2}{*}{$p$ - value } \\
\hline & & $\begin{array}{c}\text { Negative IRS } \\
\text { (5 cases) }\end{array}$ & $\begin{array}{l}\text { Weak IRS } \\
\text { (15 cases) }\end{array}$ & $\begin{array}{l}\text { Moderate IRS } \\
\text { (29 cases) }\end{array}$ & $\begin{array}{l}\text { Strong IRS } \\
\text { (11 cases) }\end{array}$ & \\
\hline $\begin{array}{c}\text { Gender } \\
\text { Female } \\
\text { Male }\end{array}$ & $\begin{array}{l}28(46.7 \%) \\
32(53.3 \%)\end{array}$ & $\begin{array}{l}2(7.1 \%) \\
3(9.4 \%)\end{array}$ & $\begin{array}{l}8(28.6 \%) \\
7(21.8 \%)\end{array}$ & $\begin{array}{l}15(53.6 \%) \\
14(43.8 \%)\end{array}$ & $\begin{array}{c}3(10.7 \%) \\
8(25 \%)\end{array}$ & 0.678 \\
\hline $\begin{array}{c}\text { Site } \\
\text { Supra-tentorial } \\
\text { Infra-tentorial }\end{array}$ & $\begin{array}{l}40(66.7 \%) \\
20(33.3 \%)\end{array}$ & $\begin{array}{l}3(7.5 \%) \\
2(10 \%)\end{array}$ & $\begin{array}{c}10(25 \%) \\
5(25 \%)\end{array}$ & $\begin{array}{l}22(55 \%) \\
7(35 \%)\end{array}$ & $\begin{array}{c}5(12.5 \%) \\
6(30 \%)\end{array}$ & 0.325 \\
\hline $\begin{array}{c}\text { Grade } \\
\text { I } \\
\text { II } \\
\text { III } \\
\text { IV }\end{array}$ & $\begin{array}{c}7(11.7 \%) \\
31(51.7 \%) \\
11(18.3 \%) \\
11(18.3 \%)\end{array}$ & $\begin{array}{c}2(28.6 \%) \\
3(9.67 \%) \\
0 \\
0\end{array}$ & $\begin{array}{c}4(57.1 \%) \\
11(35.5 \%) \\
0 \\
0\end{array}$ & $\begin{array}{c}1(14.3 \%) \\
17(54.8 \%) \\
8(72.7 \%) \\
3(27.3)\end{array}$ & $\begin{array}{c}0 \\
0 \\
3(27.3 \%) \\
8(72.7 \%)\end{array}$ & $<0.001 *$ \\
\hline $\begin{array}{c}\text { Histologic type } \\
\text { Pilocytic astrocytoma } \\
\text { Diffuse astrocytoma } \\
\text { Anaplastic astrocytoma } \\
\text { Glioblastoma multiform } \\
\text { Ependymoma } \\
\text { Anaplastic ependymoma Oligodendroglioma }\end{array}$ & $\begin{array}{l}7(11.7 \%) \\
21(35 \%) \\
9(15 \%) \\
11(18.3 \%) \\
5(8.3 \%) \\
2(3.3 \%) \\
5(8.3 \%)\end{array}$ & $\begin{array}{c}2(28.6 \%) \\
1(4.8 \%) \\
0 \\
0 \\
0 \\
0 \\
2(40 \%)\end{array}$ & $\begin{array}{c}4(57.1 \%) \\
5(23.8 \%) \\
0 \\
0 \\
3(60 \%) \\
0 \\
3(60 \%)\end{array}$ & $\begin{array}{c}1(14.3 \%) \\
15(71.4 \%) \\
6(66.7 \%) \\
3(27.3) \\
2(40 \%) \\
2(100 \%) \\
0\end{array}$ & $\begin{array}{c}0 \\
0 \\
3(33.3 \%) \\
8(72.7 \%) \\
0 \\
0 \\
0\end{array}$ & $<0.001$ * \\
\hline
\end{tabular}

$P$ - value was calculated by Mann-Whitney test. ${ }^{*} p$ - value was calculated by Kruskal Wallis test.

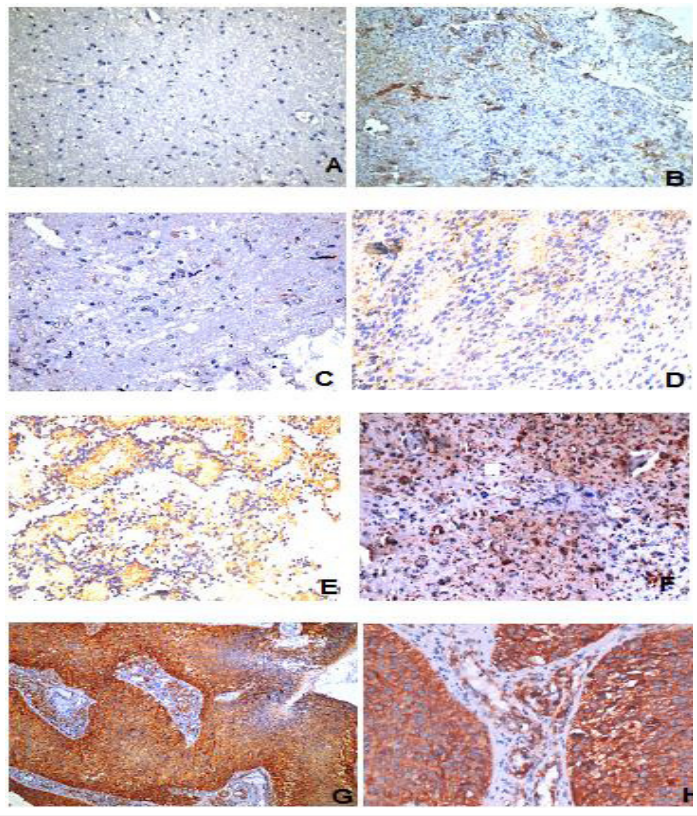

Figure 1: A) Negative Nestin expression in pilocytic astrocytoma (400x). B) Weak Nestin expression in diffuse astrocytoma (200x). C) Weak Nestin expression in oligodendroglioma (400x). D) Ependymoma with weak Nestin expression (400x). E) Moderate Nestin expression in anaplastic ependymoma (400x). F) Anaplastic astrocytoma with moderate Nestin expression (400x). G\&H) Strong Nestin expression in glioblastoma multiform (400x).

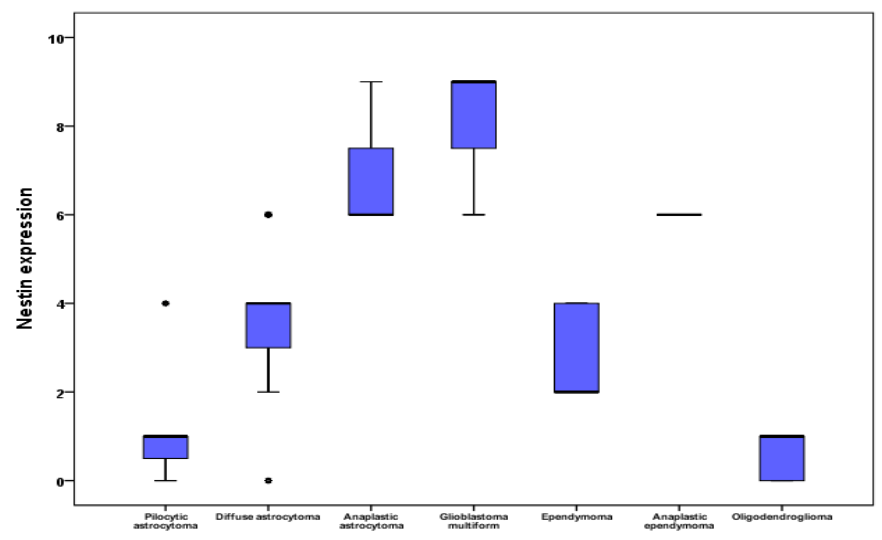

Graph 1: Correlation between Nestin expression and the histological type of tumor.

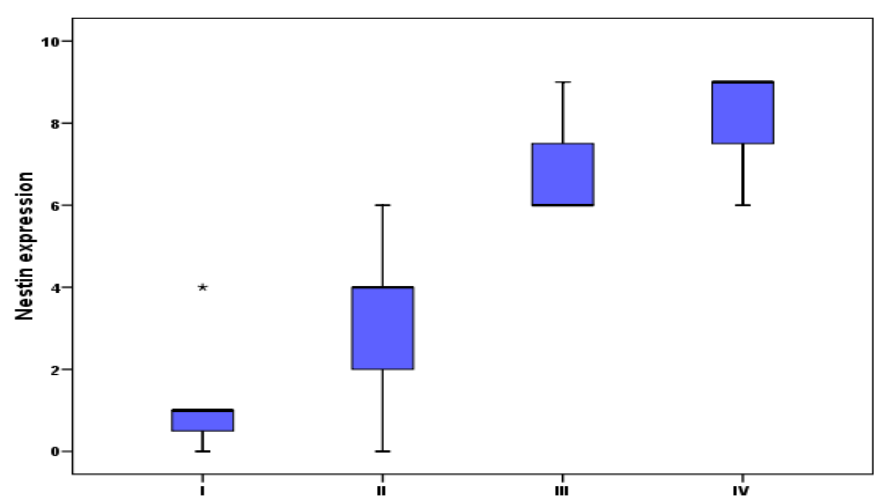

Graph 2: Correlation between Nestin expression and tumor grade.

(1.7\%) pilocytic astrocytoma. Finally, week Nestin expression was noticed in 15/60 (25\%) of studied gliomas; 3/60 (5\%) oligodendroglioma, 3/60 (5\%) ependymoma, 4/60 (6.7\%) pilocytic astrocytoma and 5/60 (8.33\%) diffuse astrocytoma. Nestin was strongly expressed in $11 / 60$ of the studied gliomas (3/11 WHO grade III and 8/11 WHO grade IV) and moderately expressed in 29/60 (1/29 WHO grade I, 17/29 WHO grade II, 8/29 WHO grade III and 3/29 WHO grade IV). Week Nestin expression were noticed in $15 / 60$ cases $(4 / 15$ WHO grade I and 11/15 WHO grade II). Our results showed a significant positive correlation between Nestin expression and histological type $(p<0.001)$ and pathological grade of gliomas $(p<0.001)$. These results are in agreement with those previously reported by Strojnik, et al. [16] who found in their study that nestin was expressed in $95.8 \%$ of 87 patients which was significantly higher in high- than in low-grade tumors $(p<$ .0001). And it was shown to be a strong prognostic marker for decreased overall survival ( $p=.0001)$ [16].

Ma, et al. [17] who confirmed that Nestin was correlated with tumor grade of the tumor in 72 cases, Kitai, et al. [18] found that 33 glioblastoma /65 different brain tumors cases were positive for Nestin, Wan, et al. [19] used tissue microarray in 283 cases of brain tumor and concluded that 
Nestin expression was correlated with tumor WHO Grade, Arai, et al. [14] studied 257 cases of brain tumors and Nestin was correlated with worse overall survival [19] as well as Hatanpaa, et al. [20], in 50 cases, and Lin, et al. [21] in 41 cases. In contrast; a previous study by Rani, et al. [22] showed that Nestin expression was noted in both low- and highgrade gliomas and did not correlate with the grade of tumor in 16 cases of brain tumors. We suggest their results may be due to application of Rabbit polyclonal anti-human Nestin in their study in contrast to monoclonal antibody used in ours which is more specific [22]. However, contradictory to our study, Chinnaiyan, et al. [23] evaluated Nestin by tissue microarray of 156 cases of glioblastoma multiform and they found no statistically significant difference in either overall survival or progression-free survival (PFS) [23] and Kim, et al. [24] concluded that Nestin is not a prognostic factor in 88 cases of glioblastoma multiform using immunohistochemical technique.

\section{Conclusion}

Increased Nestin expression is correlated with tumor progression, increasing grade, and poor prognosis of glioma. Nestin is a useful marker for detection of CSC in high-grade glioma and may serve as a predictor for patient outcomes.

\section{Recommendations}

Studying the expression of Nestin on a large number of cases, different varieties of gliomas and on surgical resection margins. Prospective studies properly powered based on this study should be undertaken to determine the significance of these findings; follow up of patients and getting enough information about response to treatment to emphasize the correlation between Nestin expression and the patient overall survival and disease outcome. Studying the change in expression of Nestin in correlation with other CSC markers (e.g CD133) to clarify their role in glioma tumorigenesis.

\section{References}

1. Tadej S. Prognostic Significance of Immunohistochemical Markers in Glioma Patients. Advances in the Biology, Imaging and Therapies for Glioblastoma. 2011; 284-285.

2. Sanai N, Chang S, Berger MS. Low grade gliomas in adults. J Neurosurg 2011; 115: 948-965

PubMed: https://www.ncbi.nlm.nih.gov/pubmed/22043865

3. Ostrom QT, Gittleman H, Fulop J, Liu M, Blanda R, et al. CBTRUS statistical report: primary brain and central nervous system tumors diagnosed in the United States in 2008-2012. Neuro-oncol. 2015; 17: 1-62. PubMed: https://www.ncbi.nlm.nih.gov/pubmed/26511214

4. Ibrahim AS, Khaled HM, Mikhail NNH, Baraka H, Kamel H. Cancer Incidence in Egypt: Results of the National Population-Based Cancer Registry Program. J Cancer Epidemiol. 2014; 437971: 1-18. PubMed: https://www.ncbi.nlm.nih.gov/pubmed/25328522

5. Li SC, Vu LT, Ho HW, Yin HZ, Keschrumrus V, et al. Cancer stem cells from a rare form of glioblastoma multiforme involving neurogenic ventricular wall. Cancer Cell Int. 2012; 12: 41.

PubMed: https://www.ncbi.nlm.nih.gov/pubmed/22995409
6. Hegi ME, Diserens AC, Gorlia T, Hamou MF, de TN, et al. MGMT gene silencing and benefit from temozolomide in glioblastoma. $\mathrm{N}$ Engl $\mathrm{J}$ Med. 2005; 352: 997-1003.

PubMed: https://www.ncbi.nlm.nih.gov/pubmed/15758010

7. Bao S, Wu Q, Li Z, Sathornsumetee S, Wang H, et al. Targeting cancer stem cells through L1CAM suppresses glioma growth. Cancer Res. 2008; 68: 6043-6048.

PubMed: https://www.ncbi.nlm.nih.gov/pubmed/18676824

8. Murre C. Helix-loop-helix proteins and the advent of cellular diversity: 30 years of discovery. Genes \& Dev. 2019; 33: 6-25.

PubMed: https://www.ncbi.nlm.nih.gov/pubmed/30602438

9. Dahlrot RH, Hermansen SK, Hansen S, Kristensen BW. What is the clinical value of cancer stem cell markers in gliomas? Int J Clin Exp Pathol. 2013; 6: 334-348.

PubMed: https://www.ncbi.nlm.nih.gov/pubmed/23412423

10. Zhang $M$, Song $T$, Yang $L$, Chen $R$, Wu L, et al. Nestin and CD133: valuable stem cell-specific markers for determining clinical outcome of glioma patients. J Exp Clin Cancer Res. 2008; 27: 8.

PubMed: https://www.ncbi.nlm.nih.gov/pubmed/19108713

11. Ishiwata T, Matsuda $Y$, Naito Z. Nestin in gastrointestinal and other cancers: effects on cells and tumor angiogenesis. World $\mathrm{J}$ Gastroenterol. 2011; 17: 409-418.

PubMed: https://www.ncbi.nlm.nih.gov/pubmed/21274370

12. Dahiya S, Lee da Y, Gutmann DH. Comparative characterization of the human and mouse third ventricle germinal zones. J Neuropathol Exp Neurol. 2011; 70: 622-633.

PubMed: https://www.ncbi.nlm.nih.gov/pubmed/21666496

13. Lépinoux-Chambaud C, Eyer J. Review on intermediate filaments of the nervous system and their pathological alterations. Histochem Cell Biol. 2013; 140: 13-22.

PubMed: https://www.ncbi.nlm.nih.gov/pubmed/23749407

14. Arai $\mathrm{H}$, Ikota $\mathrm{H}$, Sugawara $\mathrm{K}$, Nobusawa $\mathrm{S}$, Hirato J, et al. Nestin expression in brain tumors: it's utility for pathological diagnosis and correlation with the prognosis of high-grade gliomas. Brain Tumor Pathol. 2012; 29: 160-167.

15. Louis DN, Ohgaki H, Wiestler OD, Cavenee WK. WHO Classification of Tumors of the Central Nervous System. Revised $4^{\text {th }}$ ED. Lyon: IARC. 2016.

16. Strojnik T, Rosland GV, Sakariassen PO, Kavalar R, Lah T. Neural stem cell markers, Nestin and musashi proteins, in the progression of human glioma: correlation of Nestin with prognosis of patient survival. Surg Neurol. 2007; 68: 133-143.

PubMed: https://www.ncbi.nlm.nih.gov/pubmed/17537489

17. $\mathrm{Ma} \mathrm{YH}$, Mentlein R, Knerlich F, Kruse ML, Mehdorn HM, et al. Expression of stem cell markers in human astrocytoma of different WHO grades. J Neurooncol. 2008; 86: 31-45.

PubMed: https://www.ncbi.nlm.nih.gov/pubmed/17611714

18. Kitai R, Horita R, Sato K, Yoshida K, Arishima H, et al. Nestin expression in astrocytic tumors delineates tumor infiltration. Brain Tumor Pathol. 2010; 27: 17-21.

PubMed: https://www.ncbi.nlm.nih.gov/pubmed/20425043

19. Wan F, Herold-Mende C, Campos B, Centner FS, Dictus C, et al Association of stem cell-related markers and survival in astrocytic gliomas. Biomarkers. 2011; 16: 136-143.

PubMed: https://www.ncbi.nlm.nih.gov/pubmed/21323603

20. Hatanpaa KJ, Hu T, Vemireddy V, Foong C, Raisanen JM, et al. High expression of the stem cell marker Nestin is an adverse prognostic factor in WHO grade II-III astrocytoma and oligoastrocytomas. J Neuro oncol. 2014; 117: 183-189.

PubMed: https://www.ncbi.nlm.nih.gov/pubmed/24519516 
21. Lin A, Marchionni L, Sosnowski J, Berman D, Eberhart CG, et al. Role of Nestin in glioma invasion. World J Transl Med. 2015; 4: 78-87.

22. Rani SB, Mahadevan A, Anilkumar SR, Raju TR, Shankar SK. Expression of Nestin - a stem cell associated intermediate filament in human CNS tumors. Indian J Med Res. 2006; 124: 269-280.

23. Chinnaiyan P, Wang M, Rojiani AM, Tofilon PJ, Chakravarti $A$, et al. The prognostic value of Nestin expression in newly diagnosed glioblastoma: report from the Radiation Therapy Oncology Group. Radiat Oncol. 2008; 3: 32

PubMed: https://www.ncbi.nlm.nih.gov/pubmed/18817556

24. Kim KJ, Lee KH, Kim HS, Moon KS, Jung TY, et al. The presence of stem cell marker-expressing cells is not prognostically significant in glioblastomas. Neuropathology Oct. 2011; 31: 494-502.

PubMed: https://www.ncbi.nlm.nih.gov/pubmed/21269333s 